\title{
REPAIRING AND STRENGTHENING OF ELLIPTICAL PARABOLOID REINFORCED CONCRETE SHELLS WITH OPENINGS
}

\author{
N.N. MELEKA ${ }^{1}$, M.A. SAFAN ${ }^{1}$, A.A. BASHANDY ${ }^{1}$, A.S. ABD-ELRAZEK ${ }^{2}$
}

\begin{abstract}
This investigation is carried out to evaluate the repair and strengthening the techniques of elliptical paraboloid reinforced concrete shells with openings. An experimental program of several different techniques in repair and strengthening is executed. The materials, which are considered for strengthening, are; Glass fiber reinforced polymers GFRP at different position of the shell bottom surface, steel strip and external tie. They loaded by four concentrated loads affected on the corners of the opening. The initial and failure loads as well as the crack propagation for the tested shells at different loading stages, deflections and failure load for repaired and shells are recorded. A non-linear computer program based on finite element techniques is used to study the behavior of these types of shells. Geometric and materials nonlinearities are considered in the analysis. The efficiency and accuracy of computer program are verified by comparing the program results with those obtained experimentally for the control shell with opening and strengthened shells.
\end{abstract}

Keywords: Shell; Opening; Repair; Strengthening; Reinforced; Concrete.

\section{INTRODUCTION}

Shells are curved and warped or folded surfaces whose thicknesses are small compared to their other dimensions. They can cover large areas using a few numbers of supports and reduce cost compared to the other reinforced concrete systems. Shells are highly efficient structures that possess several merits over conventional engineering structures of linear geometrical shapes [1]. Shell structures of different shapes and materials are widely applied to serve many purposes. Shells are found in many industrial and engineering products such as pipes, piles, dams, tunnels, off-shore structures, chimneys, towers, bridges, storage tanks and pressure vessels. The first reinforced concrete shells were constructed about the year 1910. The Zeiss Dywidag type of cylindrical shell appeared about 1925, and the number of these structures in existence is very large [2].

Concrete is the most widely used material in shell construction; however other materials have also been used such as welded steel plates, metal decking, plywood, multiple layer timber decks, and fiberglass-reinforced plastic.

1 Civil Eng. Dep., Faculty of Eng., Menoufiya University, Egypt. e-mail: en.aab1@su.edu.eg

2 Civil Engineer, RedCo. Construction Company, Doha, Qatar. 
Defects which may appear due to unexpected conditions such as over loading, mistakes in design or construction will need suitable repair or strengthening techniques.

Radial shearing forces and moments and thus is the basis of the subsequent theoretical developments, but these equations did not be used in the practical fields until progress is done in the design methods of reinforced concrete structures [3, 4]. Love's equations did not be used till Carl Zeiss used these equations in the designing of a small reinforced concrete shell roof in 1924 in Jena, Germany. Since then many writers introduced several developments to shell theory aiming to simplify the procedures of shell analysis [3-6].

Beam method is a method which applied only to long shells [6]. The shell is assumed to act as a beam spanning longitudinally between the same supports. Since that time this method has gained popularity between the design engineers because it gives a clear and simple picture of the behavior of the shell, and because it is easy to check. The preliminary design is usually carried out by this method to obtain the approximate dimensions before carrying more calculations by the exact methods.

The earliest application of the finite element method on reinforced concrete shells is performed at 1967 [7]. In 1968, nonlinear material properties are introduced by Nilson [8], and an incremental loading technique is introduced to account for these nonlinearities. The solution is stopped when an element indicated a tensile failure, by this method Cracking is accounted for, and hence redefining a new cracked structure, which is again input into the computers reloaded incrementally. The results are checked by experimental tests. Plane stress studies are conducted for reinforced concrete structures which include elastic plastic behavior in compression as well as tensile cracking using initial stress approach [9].

Studies of reinforced concrete slabs by the emitted element method are used a progressive cracking procedure with some semi empirical moment curvature relationship [10]. Finite element method for studying prestressed concrete nuclear reactor pressure vessels treated as ax-symmetrical solids [11].

A general method of analysis which could analyze reinforced concrete slabs of arbitrary geometry and freeform shells tinder dead loads and monotonically increasing live loads. A layered triangular finite element taking account of the coupling effect between the bending action and the membrane action and he used an incremental loading procedure for the nonlinear analysis. The cracking of the concrete, the tension stiffening effect of concrete between cracks, and the nonlinear stress strain relationships for the concrete and steel reinforcement as considered nonlinear effects (Lin, 1973) [12].

The behavior and strength of three similar reinforced concrete shells under uniformly distributed loads till a definite stage of deflection, and three different techniques have been taken to repair such cracked shell. Deflection, longitudinal strains, cracking and carrying capacities of the cylindrical shells prior to cracking and after repaired are recorded, and the adequate repair system is recommended (Kamal et al, 1991) [13].

A research in a structural analysis process and rehabilitation approach for damaged, pneumatically formed reinforced concrete shell is performed by (Foraboshi et 
al, 1993) [14]. The process is applied to a seriously damaged, large span, slender shell. Special nonlinear finite element modeling is used with doubly curved and multilayer elements. Security conditions of the reference shell, including buckling collapse and damage time evolution, are analyzed; the shell exhibited unsafe behavior. The rehabilitation approach is explained in that research also prediction of the model is compared with experimental in situ tests and good agreement between both is obtained [14].

A description of an adaptive calculation scheme for nonlinear (elasto-plastic) finite element (FE) analysis is conducted by (Lackner et al, 2001) [15]. The adaptation of the FE mesh is performed by means of the h-version of mesh refinement. Before restart of the analysis after mesh refinement, the transfer of variables from the old to the new mesh must be performed. Unlike as for commonly used transfer schemes, the presented mode of transfer employ stresses and displacements for the evaluation of the state variables for the new mesh [15].

Fiber wraps are more efficient than steel strips and one layer of carbon fiber reinforced plastics wrap gave the same results as four layers of glass fiber reinforced plastics wrap. They concluded also that the repairing by changing the structural system (by adding ties) is more efficient than repairing by any other repairing techniques that it increases the initial cracking load by about $100 \%$ and the failure load by about $250 \%$ with respect to the control shells and deflection values are also decreased in different stages of loading and the failure shape in shell in case of using ties occurs at the middle of the side edge while in the other shells occurs mainly at the corners beside the supports and the computer program used provides results close enough to the experimental results for control and strengthened shells $[16,17]$.

In this research, the efficiency of different repair and strengthening techniques for reinforced concrete shells with openings are studied and compared experimentally and analytically.

\section{RESEARCH SIGNIFICANCE}

This study is carried out to investigate the behavior of shells under the effect of loads before and after repair and strengthening processes. The feasibility of using different advanced repairing and strengthening materials and techniques to rehabilitee reinforced concrete elliptical paraboloid shells with openings are studied. A nonlinear computer program based on the finite element techniques applied to study the behavior of shells. The main variables in this investigation are; repairing and strengthening materials and techniques. Failure loads, deflections at different loading stages as well as propagation of cracks for the tested shells are recorded.

The importance of this research is based on the need to know the available data addressing the behavior of elliptical paraboloid reinforced concrete shells as well as introduces different techniques for their repairing or strengthening. This research provides 
data for researchers concerning the behavior of elliptical paraboloid reinforced concrete shells and their rehabilitation.

\section{EXPERIMENTAL PROGRAM}

The conducted experimental program includes the tests carried out on different materials used either for casting the reinforced concrete shells with and without openings as well as the repairing and strengthening materials. Tested samples are shown in Table (1).

Table 1

Concrete mix used

\begin{tabular}{|c|c|c|c|c|c|c|}
\hline $\begin{array}{c}\text { Cement } \\
\left(\mathrm{kg} / \mathrm{m}^{3}\right)\end{array}$ & $\mathrm{W} / \mathrm{C}$ & $\begin{array}{c}\text { Sand } \\
\left(\mathrm{kg} / \mathrm{m}^{3}\right)\end{array}$ & $\begin{array}{c}\text { Crushed dolomite } \\
\left(\mathrm{kg} / \mathrm{m}^{3}\right)\end{array}$ & $\begin{array}{c}\text { Slump } \\
(\mathrm{mm})\end{array}$ & $\begin{array}{c}\mathrm{F}_{\text {cu 7 }} \\
\left(\mathrm{kg} / \mathrm{cm}^{2}\right)\end{array}$ & $\begin{array}{c}\mathrm{F}_{\text {cu 28 }} \\
\left(\mathrm{kg} / \mathrm{cm}^{2}\right)\end{array}$ \\
\hline 350 & 0.6 & 588.3 & 1176.6 & 80 & 230 & 340 \\
\hline
\end{tabular}

\subsection{Concrete Materials}

The cement used was the ordinary Portland cement, which was provided from the Suez factory in Egypt. A crushed dolomite with a maximum nominal size of $12 \mathrm{~mm}$, graded sand with a fineness modulus of 2.42 and tap water are used to produce the used concrete mix of shell samples as shown in Table (1). The steel used in this experimental work is the normal mild steel (St.37) as a welded mesh of rounded plain bars, $4.2 \mathrm{~mm}$ diameter. Yield stress, ultimate strength, modulus of elasticity and elongation were obtained by performing different tests. Test results are given in Table (2).

Table 2

Test results of steel reinforcement

\begin{tabular}{|c|c|c|c|c|}
\hline Steel Type & $\begin{array}{c}\text { Yield Stress } \\
\left(\mathrm{Kg} / \mathrm{cm}^{2}\right)\end{array}$ & $\begin{array}{c}\text { Tensile Strength } \\
\left(\mathrm{Kg} / \mathrm{cm}^{2}\right)\end{array}$ & $\begin{array}{c}\text { Elongation } \\
(\%)\end{array}$ & $\begin{array}{c}\text { Modulus of Elasticity } \\
\left(\mathrm{t} / \mathrm{cm}^{2}\right)\end{array}$ \\
\hline Mild steel & 3000 & 4100 & 21.9 & 2020 \\
\hline
\end{tabular}

\subsection{Concrete Shells}

Nine simply support reinforced concrete elliptical parabolic (Elpar) shells with openings are cast then, divided in to three groups. The first is control shells with central opening $20 \times 20 \mathrm{~cm}$ and without openings. The second group preloaded up to $67 \%$ of failure load then repaired using three techniques. The third group is strengthening using four different methods. Shell samples are shown in Table (3). Shells are tested 


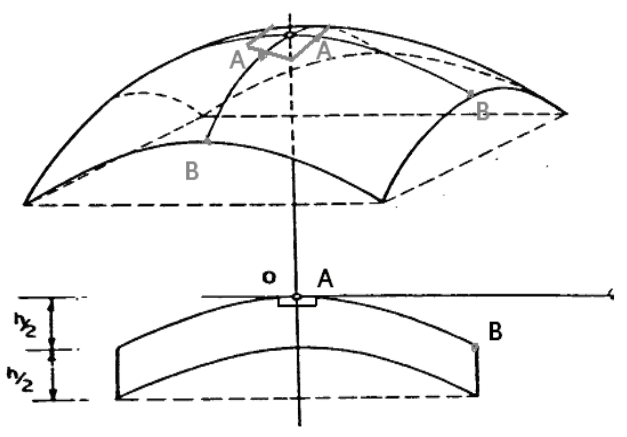

Fig. 1. The plane of elliptical paraboloid shell with central opening $0.2 \mathrm{~m} \times 0.2 \mathrm{~m}$.

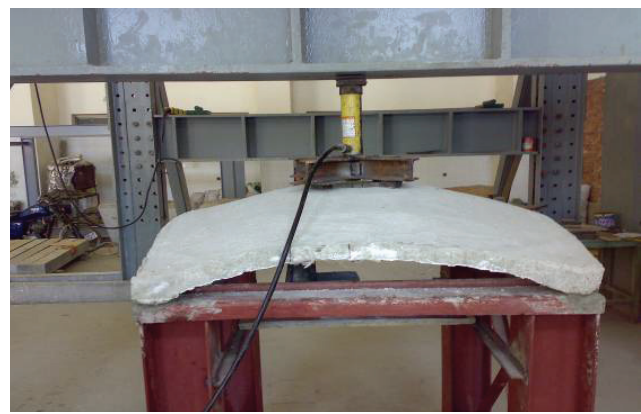

Fig. 3. The arrangement of the hydraulic jack which applying the load.

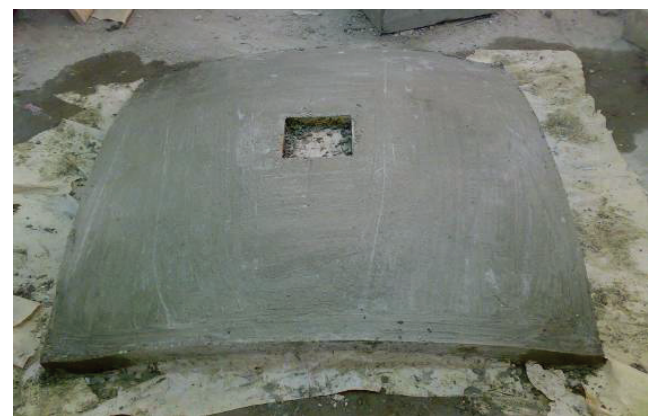

Fig. 2. Shell with central opening.

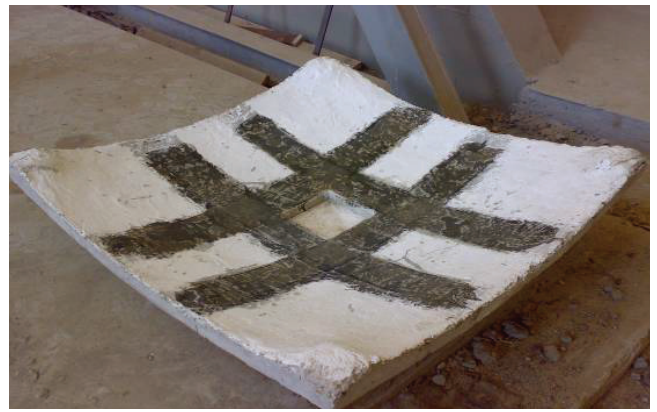

Fig. 4. Shell strengthened using 2-layers of glass fiber wrap (Type 1).

under concentrated loads as shown in Figures (1) and (3). The repaired and strengthened shells are tested by loading them up to failure load under the same first loading conditions to study the behavior and the efficiency of repairing techniques. The procedures of repair and strengthening techniques are recorded and photographed. Results of deflection for each load increments, the first cracking and failure loads are recorded. The shape and the pattern of cracks are traced for each load increments up to failure before and after the repair process. Then the tested shells are photographed to show the crack pattern.

The behavior of the materials used as well as repair and strengthening materials are estimated from the results recorded during testing of reinforced concrete shells like initial crack, deflection at each load increment at the center of opening edge at point (A) of the lower surface of each shell and at the point of the center of external edge of the shell at point (B) on the lower surface, ultimate load, crack propagation which are recorded at each stage of loading. 
Table 3

Tested shell samples

\begin{tabular}{|c|c|c|c|c|c|}
\hline Case & shell code & Description & $\begin{array}{c}\text { Dimensions } \\
(\mathrm{cm})\end{array}$ & reinforcement & $\begin{array}{l}\text { Preloading } \\
\text { value }\end{array}$ \\
\hline Control & $\mathrm{CO}$ & Control shell & \multirow{8}{*}{ 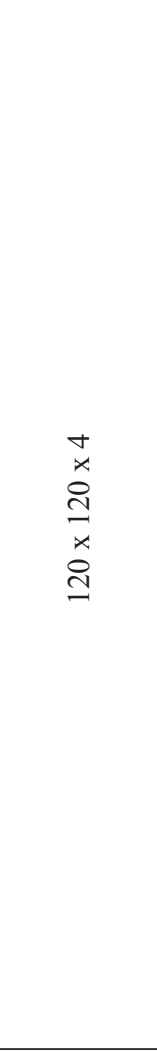 } & \multirow{8}{*}{ 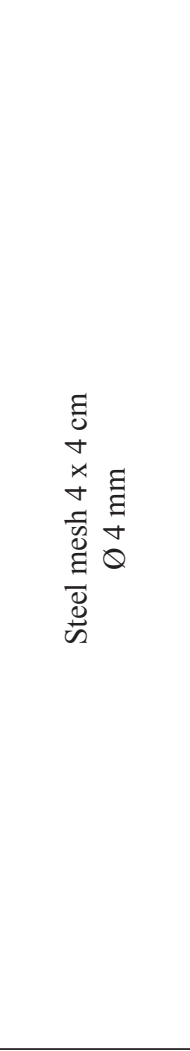 } & -- \\
\hline \multirow{3}{*}{ 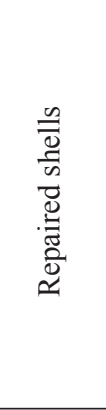 } & ROG1 & $\begin{array}{c}\text { repaired by using two layers } \\
\text { of glass fiber reinforced } \\
\text { polymers wraps G-FRP } \\
\text { (Type 1) }\end{array}$ & & & \multirow{3}{*}{ 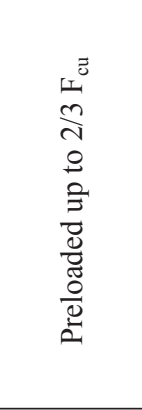 } \\
\hline & ROG2 & $\begin{array}{c}\text { repaired by using two layers } \\
\text { of glass fiber reinforced } \\
\text { polymers wraps G-FRP } \\
\text { (Type 2) }\end{array}$ & & & \\
\hline & ROS & $\begin{array}{l}\text { repaired by using one layer } \\
\text { of steel plate }\end{array}$ & & & \\
\hline \multirow{4}{*}{ 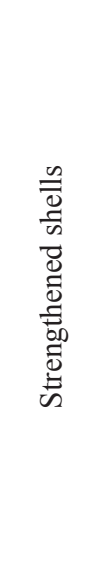 } & SOG1 & $\begin{array}{c}\text { strengthen by using } \\
\text { two layers of glass fiber } \\
\text { reinforced polymers wraps } \\
\text { G-FRP (Type 1) }\end{array}$ & & & -- \\
\hline & SOG2 & $\begin{array}{c}\text { strengthen by using } \\
\text { two layers of glass fiber } \\
\text { reinforced polymers wraps } \\
\text { G-FRP (Type 2) }\end{array}$ & & & -- \\
\hline & SOG3 & $\begin{array}{c}\text { strengthen by using } \\
\text { two layers of glass fiber } \\
\text { reinforced polymers wraps } \\
\text { G-FRP (Type 3) }\end{array}$ & & & -- \\
\hline & SOT & $\begin{array}{l}\text { strengthening by using } \\
\text { external tie }\end{array}$ & & & -- \\
\hline
\end{tabular}

\subsection{Repair and Strengthening Materials}

Steel Strips: Mild steel (St. 37) plates of dimension $100 \times 12 \times 0.15 \mathrm{~cm}$ were used. The mechanical properties are shown in Table (4). The Sikadur-31CF adhesive, as shown in Table (5), was used to fix the steel plates to the lower surface of shell as shown in Fig. (8).

Table 4

Mechanical properties of steel strips (St. 37)

\begin{tabular}{|c|c|c|c|c|}
\hline Steel Type & $\begin{array}{c}\text { Yield Stress } \\
\left(\mathrm{Kg} / \mathrm{cm}^{2}\right)\end{array}$ & $\begin{array}{c}\text { Tensile Strength } \\
\left(\mathrm{Kg} / \mathrm{cm}^{2}\right)\end{array}$ & $\begin{array}{c}\text { Elongation } \\
(\%)\end{array}$ & $\begin{array}{c}\text { Modulus of Elasticity } \\
\left(\mathrm{t} / \mathrm{cm}^{2}\right)\end{array}$ \\
\hline Mild steel & 3000 & 4100 & 21.9 & 2020 \\
\hline
\end{tabular}


Steel Resin Matrix: Sikadur-31CF is a solvent-free, thixotropic, two components adhesive and repair mortar, based on a combination of epoxy resins and specially selected high strength fillers. The resin complies to the requirements of ASTM C881-78 type 1, Grade 3 Class B + C. Sikadur- $31 \mathrm{CF}$ is available in three different grades of reactivity: rapid, normal, long pot life. Its mechanical properties are shown in Table (5).

Table 5

Mechanical properties of Sikadur-31CF

(as provided by manufacturer)

\begin{tabular}{|c|c|}
\hline Property & Value \\
\hline Compressive strength & $600-700 \mathrm{~kg} / \mathrm{cm}^{2}$ \\
\hline Adhesive strength on steel & $150-200 \mathrm{~kg} / \mathrm{cm}^{2}$ \\
\hline Adhesive strength on concrete & $35 \mathrm{~kg} / \mathrm{cm}^{2}($ concrete failure $)$ \\
\hline Modulus of elasticity & $43000 \mathrm{~kg} / \mathrm{cm}^{2}$ \\
\hline
\end{tabular}

EGlass Fiber Reinforced Polymer Wrap (GFRP-wrap) System: This system is all externally applied for strengthening and repairing of structural members. A locally available woven roving glass fiber fabric was used. Fiber used in this system is Eglass fiber. This glass fiber fabric is available in a package of woven roving glass fiber fabric with length equal or more than $50 \mathrm{~m}(\mathrm{~L} \geq 50 \mathrm{~m})$. Design thickness of the glass fiber is $0.17 \mathrm{~mm}$ based on the total area of Eglass fibers and these fibers are available in $1-\mathrm{m}$ width roll. The aerial weight is $450 \mathrm{gm} / \mathrm{m}^{2}$ to save easy handle and use. The GFRP is used for repair and strengthening of reinforced concrete structures, temper and brickworks for the purposes like changes of use or repair of defects also prevention of defects. Strengthening techniques are shown in Figures (4) to (6). Its main properties are shown in Table (5.10).

Table 6

Properties of glass fiber wrap

(as provided by manufacturer)

\begin{tabular}{|c|c|}
\hline Property & Value \\
\hline Fabric length/Roll & $>50 \mathrm{~m}$ \\
\hline Fabric width & $100 \mathrm{~cm}$ \\
\hline Fabric design thickness & $0.10 \mathrm{~mm}$ \\
\hline Areal weight & $0.45 \mathrm{~kg} / \mathrm{m}^{2}$ \\
\hline Tensile strength of fibers & $22500 \mathrm{~kg} / \mathrm{cm}^{2}$ \\
\hline Modulus of elasticity of fibers & $700 \mathrm{t} / \mathrm{cm}^{2}$ \\
\hline Strain at failure of fibers & $3.17 \%$ \\
\hline
\end{tabular}


GFRP-wrap Resin Matrix: Isophthalic polyester belonging to the Vipel ${ }^{\circledR}$ F737 series resins produced by AOC, USA was used. The resin is suitable for various fabrication processes such as hand layup, winding and pultrusion and extensively used in fabricating water pipes and other corrosion resistance applications. This resin matrix is available in a pre dosed units $(\mathrm{A}+\mathrm{B})$ with a weight of $5 \mathrm{Kg}$ with a shelf time about 18 months from manufacturing date in original packing stored at temperatures from $+5^{\circ} \mathrm{C}$ to $+25^{\circ} \mathrm{C}$. The pot life of the mixture are $15^{\circ} \mathrm{C}: 90 \mathrm{~min} .(5 \mathrm{~kg})$ and $35^{\circ} \mathrm{C}: 30 \mathrm{~min}$ $(5 \mathrm{~kg})$ where as the open time is $30 \mathrm{~min}$. (at $\left.+35^{\circ} \mathrm{C}\right)$. Application temperature is ranged from $+15^{\circ} \mathrm{C}$ to $+35^{\circ} \mathrm{C}$ of the ambient atmosphere. The resin has excellent mechanical properties in terms of tensile strength $(86 \mathrm{MPa})$, tensile modulus $(3.4 \mathrm{GPa})$ and tensile elongation (4.0\%) according to ASTM D638 test method and has a specific gravity of 1.12 as reported by the manufacturer.

\subsection{Repairing and Strengthening Methodology}

The repairing or strengthening procedures using GFRP-wrap are executed in three types; type 1 as shown in Fig. (4), type 2 as shown in Fig. (5) and type 3 as shown in Fig. (5). The repairing or strengthening procedures using GFRP-wrap are performed as follows:

1. The tension side of the reinforced concrete shell is roughened and prepared by removing any loose materials or dirt from crack by using compressed air.

2. GFRP wrap are cleaned and cut with a cutter or a very sharp knife into $10 \mathrm{~cm}$ width strips $\times 100 \mathrm{~cm}$ length (width nearly $10 \%$ of the span each side) then the adhesive polymer is mixed.

3. The resin is applied on the tension surface by polymers laminating roller then the wrap are placed into the resin coating and then putting on the coated concrete surface. The rollers are used until the resin is squeezed out between the rolling to be sure the GFRP wrap are bonded to the tension surface of shell.

4. The shell are left for 8 days then, tested.

The strengthening procedures using steel strips are executed as follows:

1. The steel sheets of $1.5 \mathrm{~mm}$ thickness are cut into strips of dimension $100 \times 12 \mathrm{~cm}$.

2. The shell tension surface is roughened and prepared by removing loose materials and dirt from crack by using of compressed air.

3. Steel strips are cleaned and painted with anti corrosion paint.

4. Steel strips are fixed to the tension surface of slabs by using Sikadur31CF. Uniform pressure on the steel plates is established through the steel bolts to assure complete contact between the steel strips.

5. Steel bolts is used to grip the steel strips to the slab and prevent void formation between the steel strips and the adhesive material (Sikadur 31CF).

6. The excess amount of Sikadur $31 \mathrm{CF}$ is removed.

7. The slabs are left 10 days and then tested. 


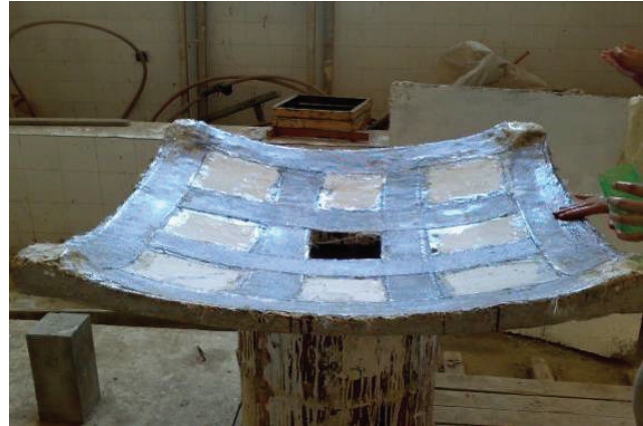

Fig. 5. Shell strengthened using 2-layers of glass fiber wrap (Type 2).

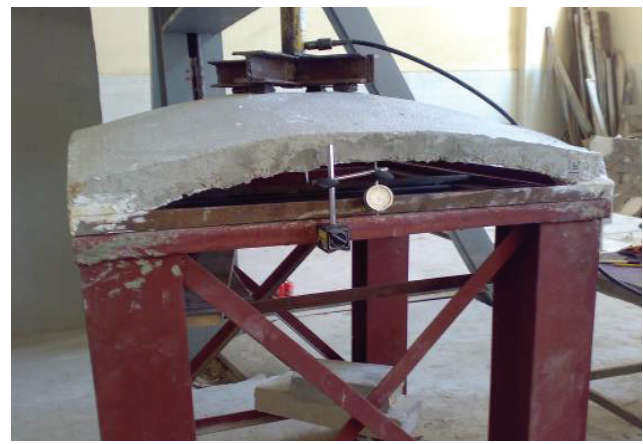

Fig. 7. Shell strengthened by using external tie.

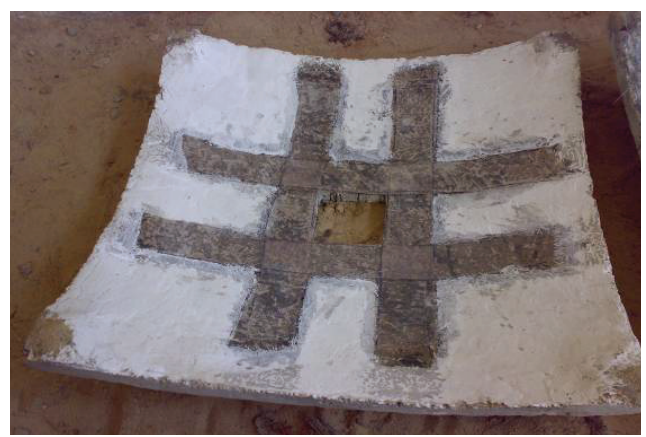

Fig. 9. Repaired shell by using 2-layers of glass fiber wrap (Type 1).

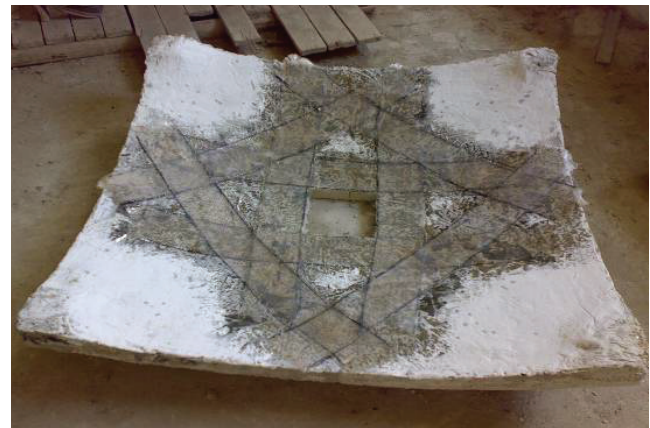

Fig. 6. Shell strengthened using 2-layers of glass fiber wrap (Type 3).

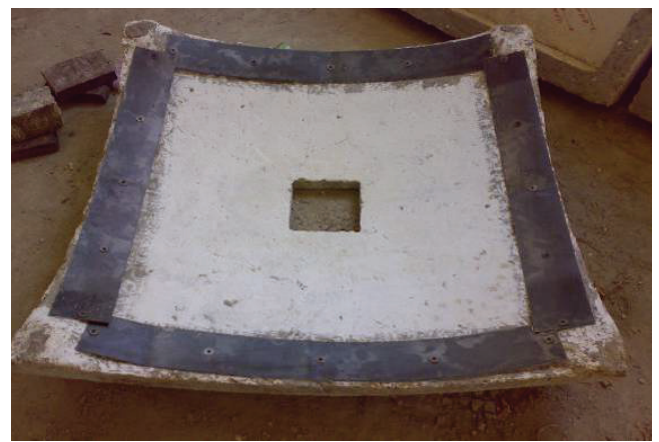

Fig. 8. Repaired shell by using steel strip.

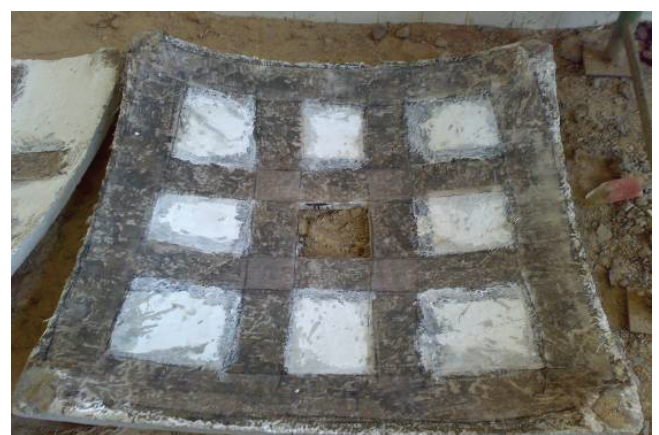

Fig. 10. Repaired shell by using2-layers of glass fiber wrap (Type 2). 
Rigid external ties are used as a stiffener for the shell supports. The ties are made from steel angles of section $5 \times 5 \times 0.5 \mathrm{~mm}$ and length $120.3 \mathrm{~cm}$, welded together and stiffened at corners by adding plate of thickness $2 \mathrm{~mm}$ welded to the both connecting angles, forming a rigid supporting frame of dimension $120.3 \times 120.3 \mathrm{~cm}$. The shell is fixed in to that steel tie frame then it is tested.

The efficiency of different materials used in repair and strengthening of reinforced concrete shells depends mainly on the material behavior. The efficiency can be expressed by some terms like deflection, initial cracking load, and failure (ultimate) load, mode of failure and crack behavior.

\section{Finite ELEMENT ANALYsis}

Several researchers $[3,7-10,12$ and 16] have studied the nonlinear analysis of shells. A nonlinear computer program based on the finite element techniques applied to study the behavior of shells. Geometric and material nonlinearities have been considered. The material nonlinearities are taken into consideration. The nonlinearities include the stress-strain relationship for concrete and steel reinforcement, concrete cracking and tension stiffening effects. The efficiency and accuracy of the computer program are verified by comparing its results with the experimental results.

A nonlinear finite element FE computer program performed by (Meleka, 1995) [18] is used. In the nonlinear finite element computer program, for each node of the finite element mesh there are five degree of freedom, three displacements in $\mathrm{X}, \mathrm{Y}$ and $\mathrm{Z}$ directions and two rotations about $\mathrm{X}$ and $\mathrm{Y}$ axis. Boundary conditions which are taken in consideration are as follows:

The shell is assumed to support on three nodes for each corner. Finite element mesh is $12 \times 12$ elements as the dimensions of the tested shell are $120 \times 120 \mathrm{~cm}$ as shown in Fig. (26). Every direction is consists of 12 elements of $10 \mathrm{~cm}$ length for each as shown in Fig. (27).

For support (A), nodes „3",,39","41" is restrained only in $\mathrm{X}$ and $\mathrm{Z}$ directions while free in $\mathrm{Y}$ direction also the rotation about $\mathrm{Y}$ axis is permitted. At support (B), node ,23","61","63" is restrained only in X and Z directions while free in Y direction also the rotation about $Y$ axis is permitted. At support (C), node ,419","421","459" is restrained in $\mathrm{X}, \mathrm{Y}$, and $\mathrm{Z}$ direction also the rotation about $\mathrm{X}$ and $\mathrm{Y}$ axis is permitted. At support (D), node ,441","443","479"'is restrained in X, Y and Z directions also the rotation about $\mathrm{X}$ and $\mathrm{Y}$ axis is restrained as shown in Figures (27) and (28).

The control shell $[\mathrm{CO}]$ is analyzed by the computer program based on the nonlinear finite element analyses which based on the nonlinear finite element method. The dimension of this tested shell is $120 \times 120 \times 4 \mathrm{~cm}$ is supported on its four corners. The reinforcements are a welded steel mesh of diameter $\varphi 4.2 \mathrm{~mm}$ and the spacing between bars is $5.8 \mathrm{~cm}$ in each direction. A concentrated load is divided in to four concentrated 
loads applied at the four edges of the opening of shell. The load increment is applied by $250 \mathrm{~kg}$ up to failure. The material properties and dimensions are:

1. Height of the side curve parabola in both directions $=12.5 \mathrm{~cm}$

2. Height of the crown at the center of the shell $=25 \mathrm{~cm}$

3. Concrete compressive strength $\mathrm{C}_{28}=340 \mathrm{~kg} / \mathrm{cm}^{2}$

4. Modulus of rupture of concrete $\mathrm{f}_{\mathrm{t}}=35 \mathrm{~kg} / \mathrm{cm}^{2}$

5. Yield strength of steel $\mathrm{f}_{\mathrm{y}}=3000 \mathrm{~kg} / \mathrm{cm}^{2}$

6. Young's modulus of steel $\mathrm{E}_{\mathrm{s}}=2.1 \times 10^{6} \mathrm{~kg} / \mathrm{cm}^{2}$

7. Young's modulus of concrete $\mathrm{E}_{\mathrm{c}}=2 \times 10^{5} \mathrm{~kg} / \mathrm{cm}^{2}$

8. Poisson's ratio $\mathrm{v}=0.2$

9. Concrete cover $\mathrm{c}=0.5 \mathrm{~cm}$

The properties of the strengthened shell are the same as before and the glass fiber reinforced polymer wrap GFRP properties are:

1. GFRP-wrap width $\mathrm{z}=10 \mathrm{~cm}$

2. GFRP-wrap thickness/layer $=0.1 \mathrm{~cm}$

3. Tensile strength of GFRP $=22500 \mathrm{~kg} / \mathrm{cm}^{2}$

4. Yield strength of resin $=2450 \mathrm{~kg} / \mathrm{cm}^{2}$

5. Fibers modulus of elasticity $=700000 \mathrm{~kg} / \mathrm{cm}^{2}$

6. Resin modulus of elasticity $=43000 \mathrm{~kg} / \mathrm{cm}^{2}$

7. Young's modules of GFRP $=210000 \mathrm{~kg} / \mathrm{cm}^{2}$

The boundary conditions of strengthened shell is the same as given before but the layer system is arranged to simulate the effect of using two layers of glass fiber reinforced polymers wrap GFRP. To represent the addition 2 layers of GFRP wrap, the outer elements are considered to be with addition number of layers of the GFRP as shown in Fig. (28). Each layer had a $10 \mathrm{~cm}$ width and $0.1 \mathrm{~cm}$ thickness.

\section{Test REsUlts}

Load-deflection curves at point (A) of different strengthened shells compared to the control shell with central opening CO are shown in Fig. (12) while at point (B) are shown in Fig. (13). Load-deflection curves of different repaired shells at points (A) and (B) respectively are shown in Figures (14) and (15). Initial cracking loads and failure loads for each type of strengthened and repaired shells are shown in Figures (16) and (17).

\subsection{Deflection of Tested Shells}

\section{A-Deflections of Strengthened Shells}

The behavior of the strengthened shells is improved in the used two different techniques. Deflections decreased in all stages of loading with respect to the control shell. 


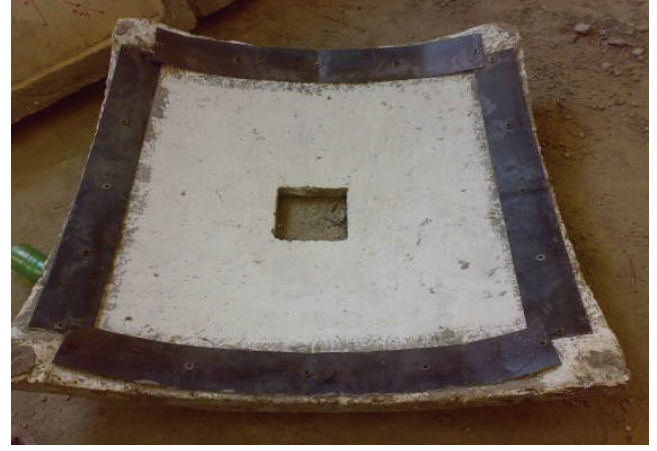

Fig. 11. Bolts arrangement on the lower face of the shell repairing by using steel plates.

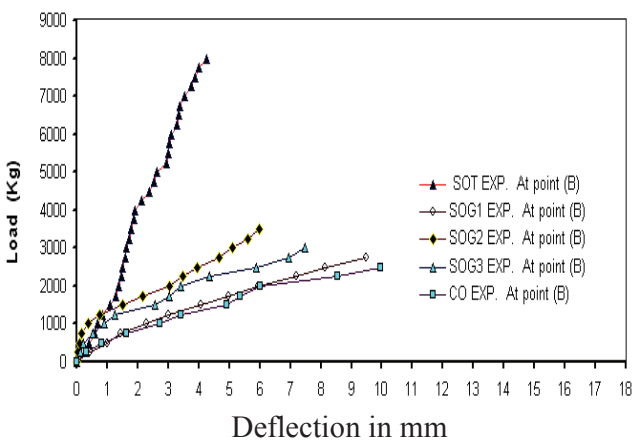

Fig. 13. Deflection values of strengthened shells at point (B).

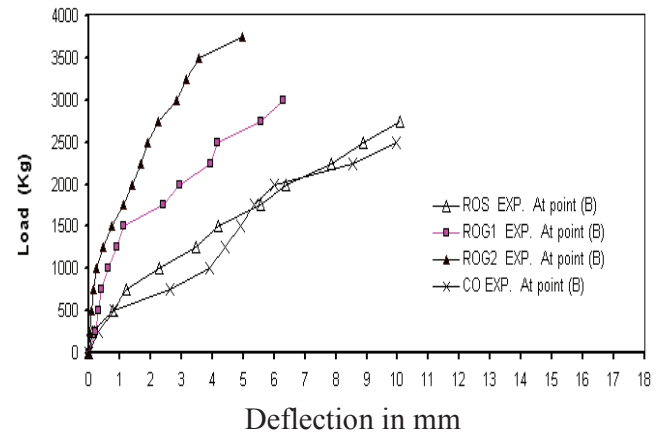

Fig. 15. Deflection values of repaired shells at point (B)

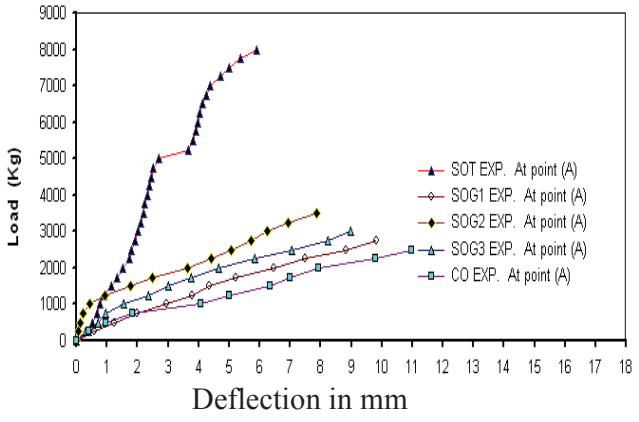

Fig. 12. Deflection values of strengthened shells at point (A).

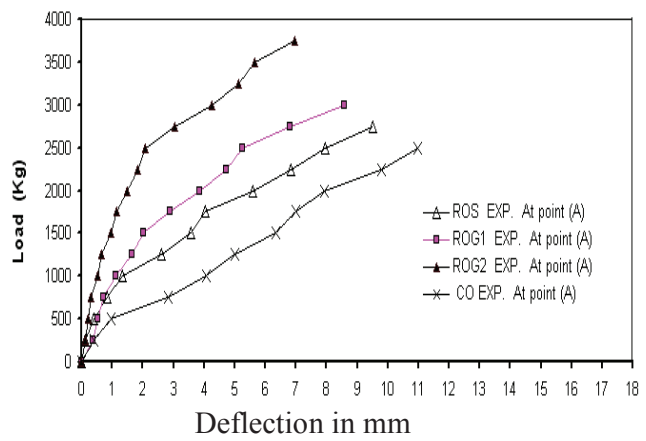

Fig. 14. Deflection values of repaired shells at point (A).

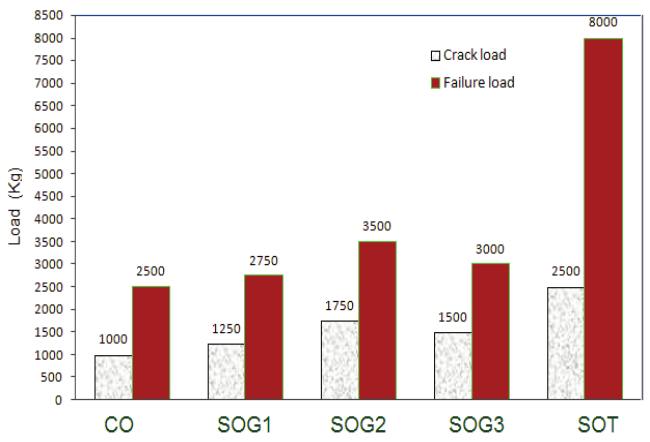

Fig. 16. Initial cracking load and failure loads for strengthened shells. 
At the initial cracking load of the control shell $\mathrm{CO}$, the deflections of the strengthened shell using external ties, SOT are decreased by $55.6 \%$ and $61.5 \%$ at point (A) and (B) respectively with respect to the control shell. At the ultimate load of the control shell, the deflections of the strengthened shell using external ties are decreased by about $46.3 \%$ and $53.5 \%$ at points (A) and (B) respectively.

For the second shell which is strengthened by using two layers of glass fiber reinforced polymers wraps GFRP-wrap (Type 1), SOG1, the deflection are decreased. At the initial cracking load of the control shell $\mathrm{CO}$, at points (A) and (B) deflection are decreased by about $6.6 \%$ and $23.2 \%$ respectively, while at the failure load of the control shell CO, deflections are decreased by about $10.5 \%$ and $4.5 \%$ at points (A) and (B) respectively with respect to the control shell.

For the third shell which is strengthened by using two layers of GFRP-wrap (Type 2), SOG2, the deflection values are decreased. At the initial cracking load of the control shell CO, at points (A) and (B) deflection are decreased by about $38.5 \%$ and $45.1 \%$ respectively, while at the failure load of the control shell $\mathrm{CO}$, deflections are decreased by about $28.2 \%$ and $39.8 \%$ at points (A) and (B) respectively with respect to the control shell.

For the fourth shell which is strengthened by using two layers of GFRP-wrap (Type 3), SOG3, the deflection values are decreased. At the initial cracking load of the control shell CO, at points (A) and (B) deflection are decreased by about $25.5 \%$ and $34.2 \%$ respectively, while at the failure load of the control shell $\mathrm{CO}$, deflections are decreased by about $18.3 \%$ and $24.8 \%$ at points (A) and (B) respectively with respect to the control shell.

\section{B - Deflections of Repaired Shells}

The behavior of the repaired shells is improved in the different repair techniques. Deflections decreased in the most stages of loading with respect to the control shell and increased in two readings only as following.

At the initial cracking load of the control shell $\mathrm{CO}$, the deflections of the repaired shell using two layer of GFRP-wrap (Type 1), ROG1, is decreased at point (A) by $29.2 \%$ and it is decreased at point (B) by $38.5 \%$ with respect to the control shell CO, and at the ultimate load of the control shell, the deflections are decreased by about $21.8 \%$ and $36.7 \%$ at points (A) and (B) respectively.

For the second shell which is repaired by using two layers of GFRP-wrap (Type 2), ROG2, the deflections are also decreased. At the initial cracking load of the control shell $\mathrm{CO}$, at points (A) and (B) deflections are decreased by about $50.4 \%$ and $52.1 \%$ respectively, while at the failure load of the control shell $\mathrm{CO}$, deflections are decreased by about $36.7 \%$ and $50 \%$ at points (A) and (B) respectively with respect to the control shell.

For the third shell which is repaired by using steel plates ROS, at the initial cracking load of the control shell CO, the deflection value is decreased at point (A) by $12.5 \%$ but 
it is increased at point (B) by $6.2 \%$ with respect to the control shell $\mathrm{CO}$, while at the failure load of the control shell $\mathrm{CO}$, deflections are decreased by about $13.5 \%$ at point (A) but it is increased at point (B) by about $1.2 \%$ with respect to the control shell CO.

\subsection{Cracking Loads}

For all investigated reinforced concrete shells the cracking behavior and cracking patterns are improved by repair or strengthening. Cracking loads and failure loads of strengthened and repaired shells are recorded as shown in Figures (16) and (17).

Figure (16) shows that, for the strengthened shell by using external ties SOT, the initial cracking load is increased by about $150 \%$ with respect to the control shell CO. For the second shell which is strengthened by using two layers of GFRP-wrap (Type 1), SOG1, the initial cracking load is increased by about $25 \%$ with respect to the control shell CO. For the third shell which is strengthened by using two layers of GFRP-wrap (Type 2), SOG2, the initial cracking load is increased by about $75 \%$ with respect to the control shell $\mathrm{CO}$. For the fourth shell which is strengthened by using two layers of GFRP-wrap (Type 3), SOG3, the initial cracking load is increased by about $50 \%$ with respect to the control shell $\mathrm{CO}$. previous result are in agreement with previous researches $[16,17]$

From Fig. (17) it is noticed that, the shell which is repaired by using two layer of glass fiber reinforced polymers wrap G-FRP (Type 1), ROG1, the initial cracking load is increased by about $75 \%$ with respect to the control shell CO. In the shell which repaired by using two layer of GFRP-wrap (Type 2), ROG2, the initial cracking load is increased by about $150 \%$ with respect to the control shell CO.

In the shell which repaired by using steel plates ROS, the initial cracking load is increased by about $50 \%$ with respect to the control shell $\mathrm{CO}$.

\subsection{CRack Patterns}

The crack patterns are recorded, illustrated and photographed at each load increment. The number of cracks is decreased in all cases of repair and strengthening used in this research in agreement with previous researches $[16,17]$. The improvement in the cracking behavior depends on the method of repair or strengthening. The crack pattern for all shells is shown in Figures (18) to (25).

\subsection{Failure Loads for Strengthened and Repaired Shells}

For strengthened shells the initial cracking loads and failure loads are shown in Fig. (16). For repaired shells the initial cracking loads and failure loads values comparing to control shell deflection are shown in Fig. (17).

The failure load of the shell which is strengthened by using external ties SOT is increased by about $220 \%$ with respect to the control shell CO as noticed in Fig. (16). 


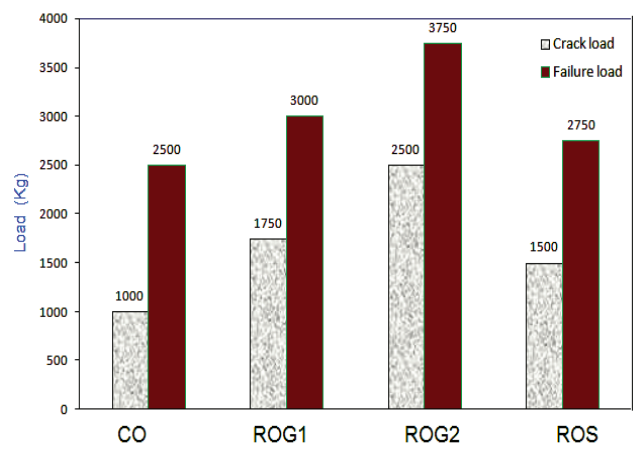

Fig. 17. Initial cracking load and failure loads for control and repaired shells.

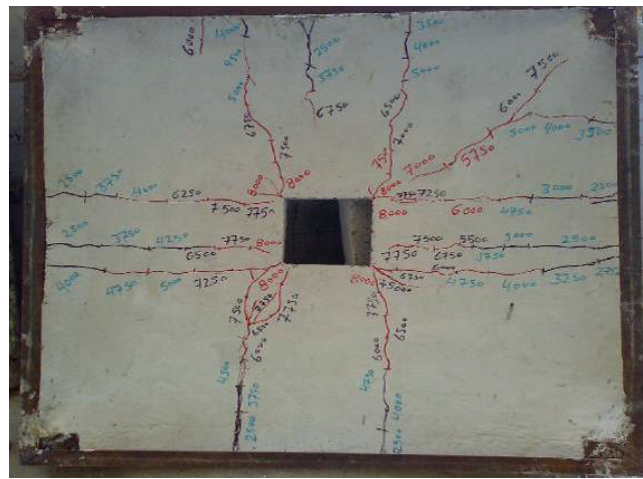

Fig. 19. Crack pattern of shell strengthened by external tie (SOT).

[Failure load $=8000 \mathrm{~kg}$ ]

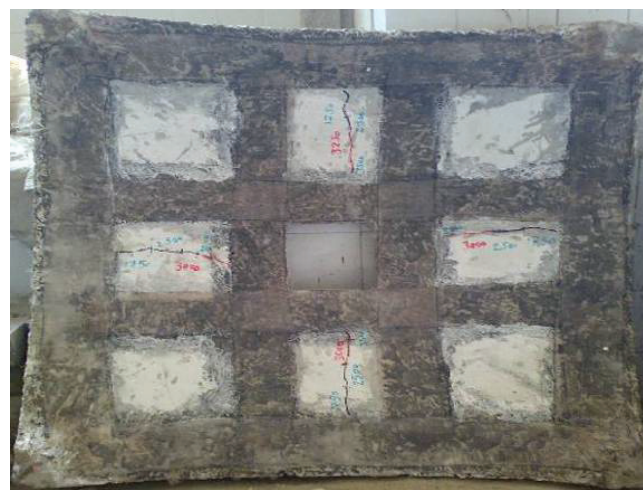

Fig. 21. Crack pattern of shell Strengthened by using 2 layers GFRP (Type 2).

[Failure load $=3500 \mathrm{~kg}$ ]

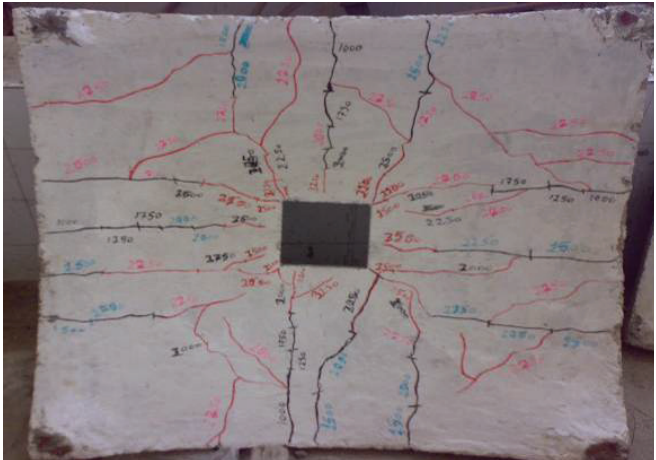

Fig. 18. Crack pattern of the control shell (CO). [Failure load $=2500 \mathrm{~kg}$ ]

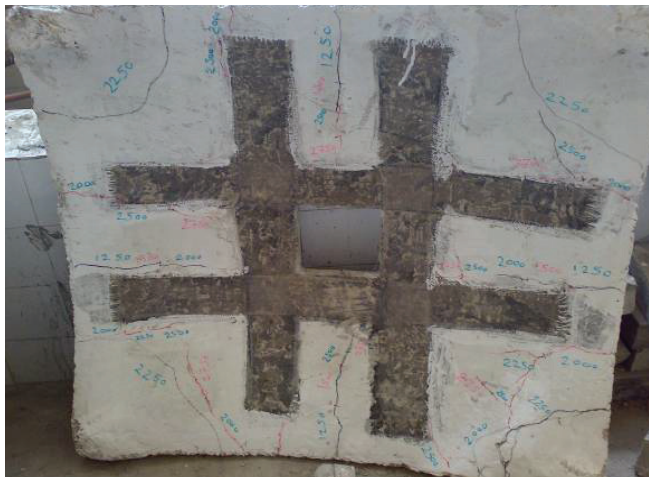

Fig. 20. Crack pattern of shell Strengthened by using 2 layers GFRP (Type 1).

[Failure load $=3500 \mathrm{~kg}$ ]

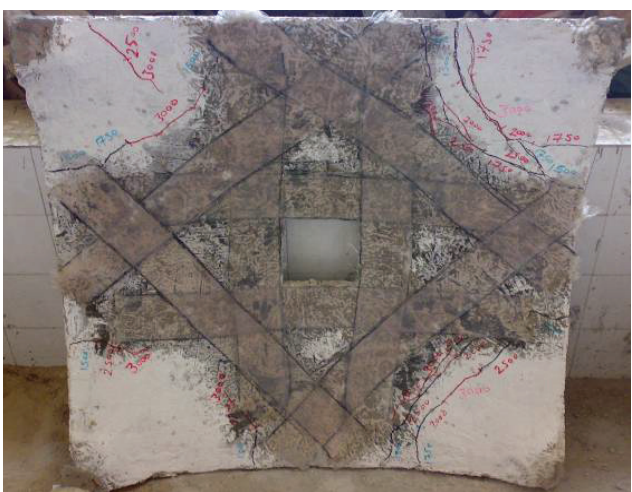

Fig. 22. Crack pattern of shell Strengthened by using 2 layers of GFRP (Type 3).

[Failure load $=3500 \mathrm{~kg}$ ] 


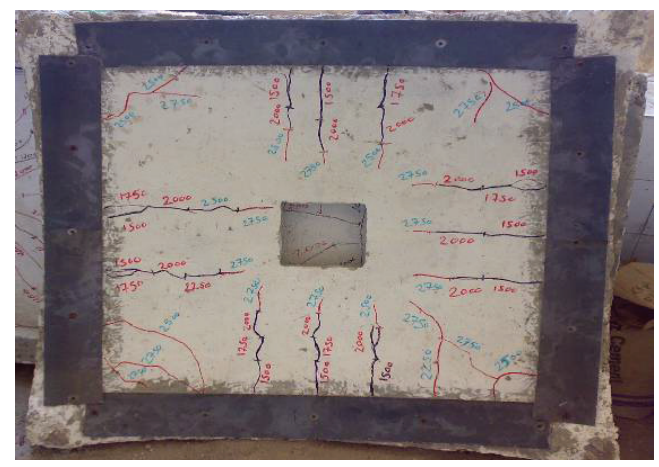

Fig. 23. Crack pattern of repaired by steel plate. [Failure load $=2750 \mathrm{~kg}$ ]

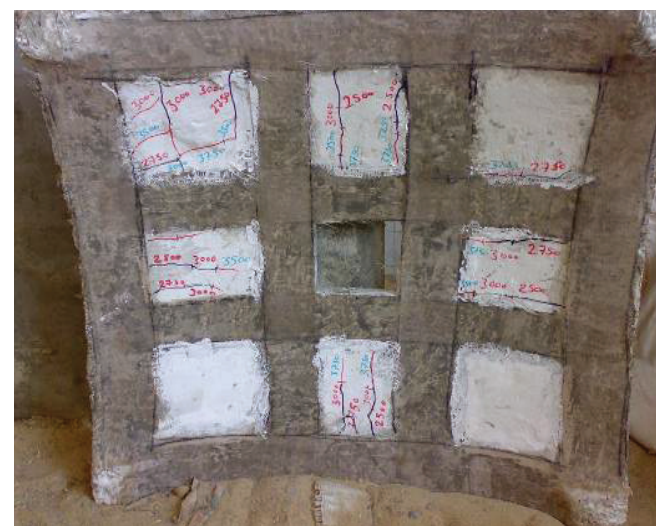

Fig. 25. Crack pattern of shell repaired by using 2 layers GFRP (Type 2).

[Failure load $=3750 \mathrm{~kg}$ ]

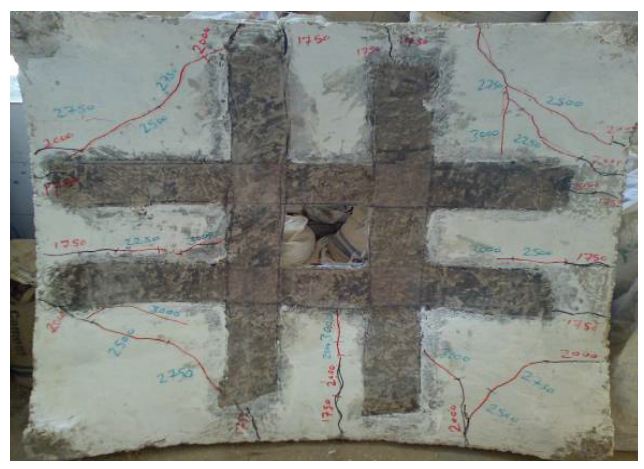

Fig. 24. Crack pattern of shell repaired by using 2 layers of GFRP (Type 1).

[Failure load $=3000 \mathrm{~kg}$ ]

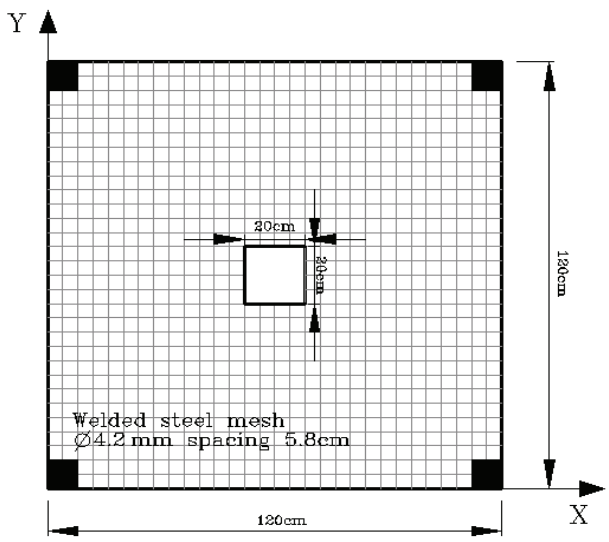

Fig. 26. Dimensions and reinforcement of the shell.

For the second shell which is strengthened by using two layers of glass fiber reinforced polymers wraps G-FRP (Type 1), SOG1, the failure load is increased by about $10 \%$ with respect to the control shell CO. For the third shell which is strengthened by using two layers of GFRP-wrap (Type 2), SOG2, the failure load is increased by about $40 \%$ with respect to the control shell CO. For the fourth shell which is strengthened by using two layers of GFRP-wrap (Type 3), SOG3, the failure load is increased by about $20 \%$ with respect to the control shell CO. All previous results indicated that, the strengthened shells are carrying extra loads compared to the control shells.

From Fig. (17), it is noticed that the shell which is repaired by using two layer of GFRP-wrap (Type 1), ROG1, failure load is increased by about $20 \%$ with respect to 


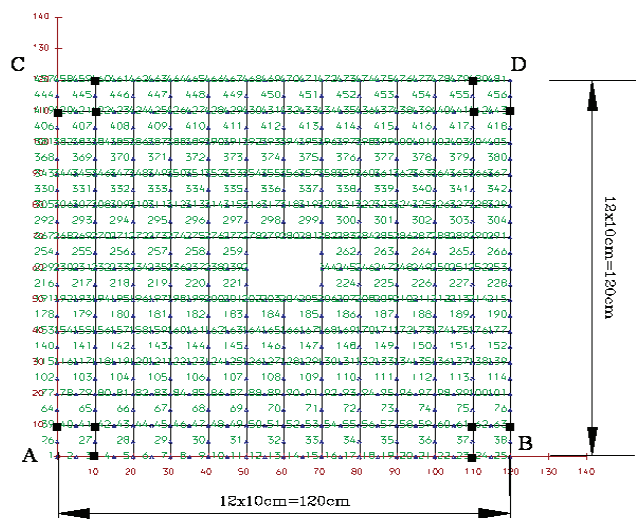

(a) In plan.

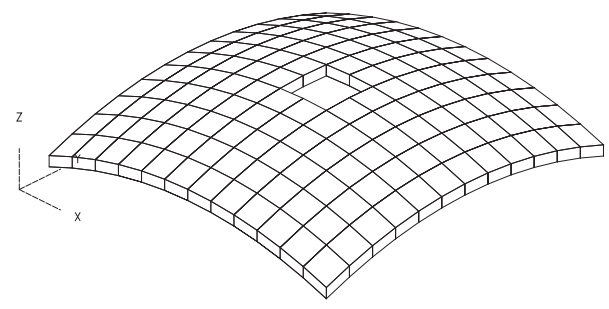

(b) In 3-dimensions $(120 \mathrm{~cm} \times 120 \mathrm{~cm})$.

Fig. 27. Finite element mesh $12 \times 12$

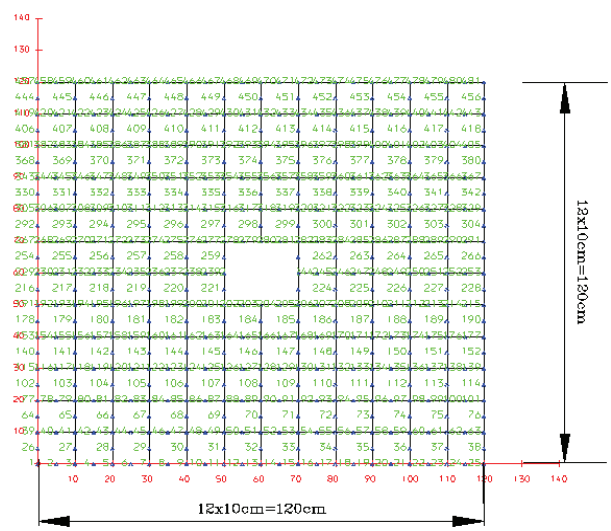

(a) Finite element mesh.

(b)

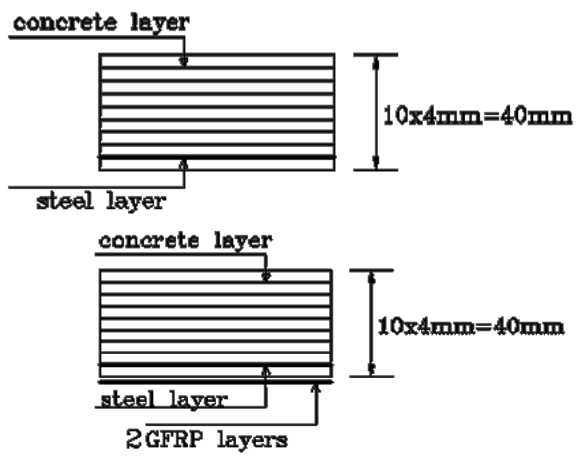

(c) Layered system for control and strengthened.

Fig. 28. Finite element meshes and layer system for model.

the control shell CO. In the shell which repaired by using two layer of GFRP-wrap (Type 2), ROG2, the failure load is increased by about $50 \%$ with respect to the control shell CO. In the shell which repaired by using steel plates ROS, the failure load is increased by about $10 \%$ with respect to the control shell $\mathrm{CO}$. All previous results indicated that, the repaired shells are carrying extra loads compared to the control shells.

\subsection{Comparison between Finite Element Analysis and Experimental Results}

The control shell $\mathrm{CO}$ is analyzed using FE and named as COF. The shell strengthened by using 2 layer of glass fiber reinforced polymers wrap GFRP (type $1 \rightarrow$ SOG1), (type $2 \rightarrow$ SOG2) and (type $3 \rightarrow$ SOG3) is analyzed by the FE computer program based on the nonlinear finite element analyses and named as SOG1F, SOG1F and SOG1F respec- 

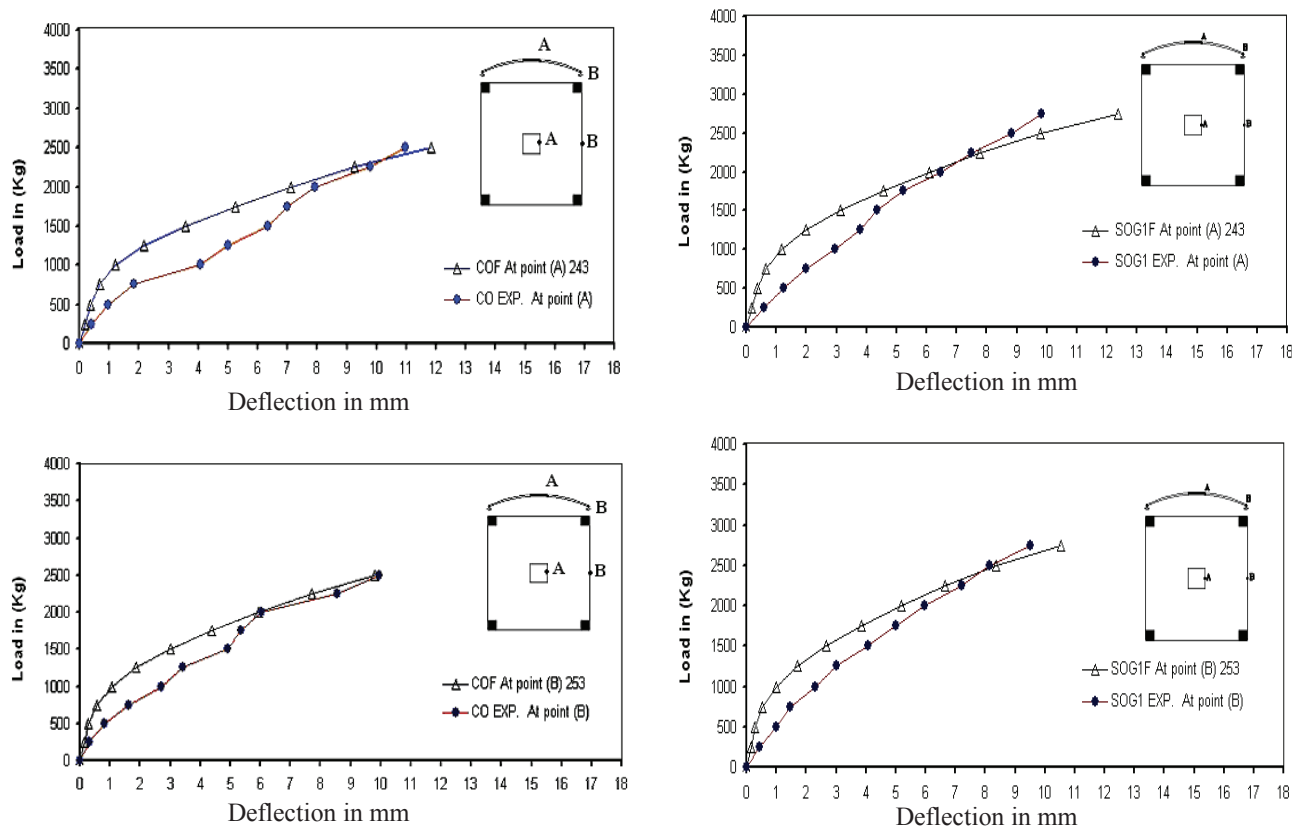

Fig. 29. Deflection values of control shell [CO] compared to $\mathrm{FE}$ model $[\mathrm{COF}]$ at points (A) and (B).

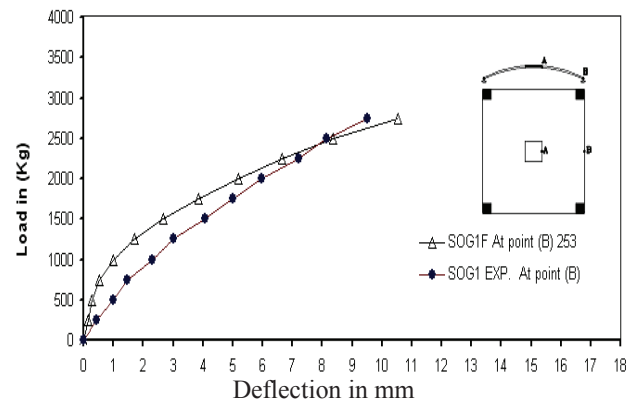

Fig. 30. Deflection values of strengthened shell [SOG1] compared to FE model [SOG1F] at points (A) and (B).

tively. The obtained results are compared with the experimental results. Test results are shown in Figures (29) to (32). The results of the nonlinear analysis come close to the experimental results. Results of FE analysis are nearly in agreement with (Bashandy, 2004) [16].

\section{Conclusions}

Based on the available research results, the following main conclusions for the repairing and strengthening of reinforced concrete elliptical paraboloid shells as follows:

1. The using of shells without any opening is more efficient than using shell with a central opening as the failure load increased by about $14 \%$.

2. The behavior of the strengthened shells is improved in the used two different techniques. Deflections decreased in all stages of loading with respect to the control shell.

3. The technique suggested in this research which depends on using fiber reinforced polymer wraps increase the value of the initial cracking and failure loads and decrease the deflection in repaired shells compared to control shell. 

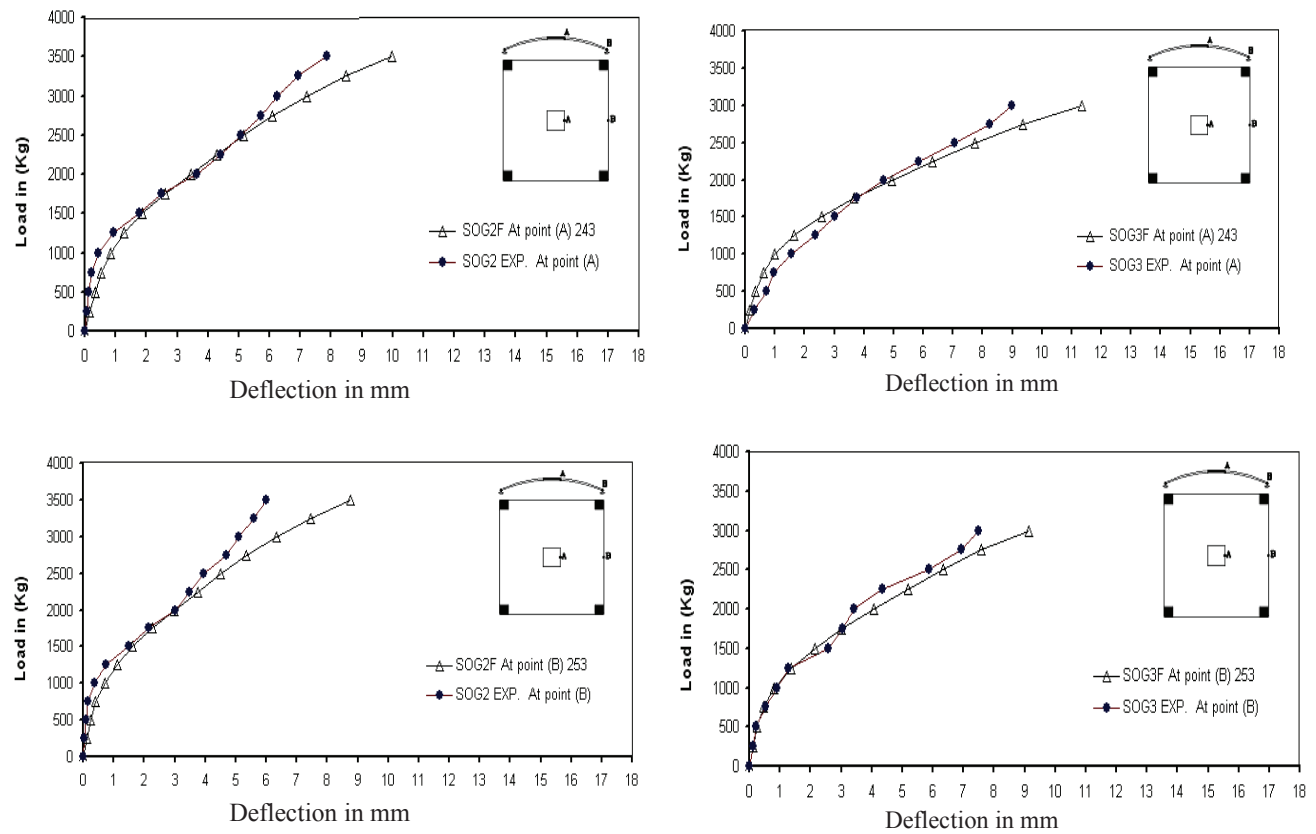

Fig. 31. Deflection values of strengthened shell [SOG2] compared to FE model [SOG2F] at points (A) and (B).

Fig. 32. Deflection values of strengthened shell [SOG3] compared to FE model [SOG3F] at points (A) and (B).

4. Using of fiber reinforced polymer GFRP wrap is more efficient than using steel strips because GFRP provides higher rigidity and easier in applying and adhering.

5. Use of fiber reinforced polymer GFRP wrap in diagonal direction is better than using it around the opening only as the failure load increased by about $10 \%$.

6. Use of fiber reinforced polymer GFRP wrap around the opening and external edges is better than using it around the opening only because failure load increased by about $20 \%$.

7. The suggested FE model for strengthening shells is quite accurate in representing the problem.

8. The developed FE computer program can be applied to study different cases of strengthening that are not included in this experimental program with and without openings. 


\section{REFERENCE}

1. Fung, Y.C. and Sechler, E.E., „Thin-Shell Structures”, Prentic-Hall, Englewood Cliffs, New Jersey, USA, 1974.

2. Paduart, A., „Shell Roof Analysis”, Professeur a' I'université Libre de Bruxelles, New Delhi,1967.

3. Bell, J.C., and Elms, D., „Partially Cracked Finite Elements”, Journal of the Structural Division, ASCE, Vol. 97, No. ST7, July 1971.

4. Faber, C. and Candela, F., „The Shell Builder”, Reinhold Publishing Corporation, New York, 1963.

5. Flugge, W., „Stresses in Shells”, SpringerVerlag OHG, Berlin, 1960.

6. Jenkins, R.S, „Theory and Design of Cylindrical Shell Structures”, London, UK, 1947.

7. Ngo, D. and Scordelis, A.C., „Finite Element Analysis of Reinforced Concrete Seams”, ACI Journal, No. 64, March, 1967.

8. Nilson, A.H., „Nonlinear Analysis of Reinforced Concrete by the Finite element Method”, ACI Journal, Vol. 65, No. 9, September 1968.

9. Valliappan, S., and Doolan, T.F., „Nonlinear Stress Analysis of Reinforced Concrete”, Journal of Structure Division, ASCE, Vol. 98, No. ST4, April 1972.

10. Jofriet, J.C. and McNiece, G.M., „Finite Element Analysis of Reinforced Concrete Slabs”, Journal of the Structural Division, ASCE, Vol. 97, No. ST3, Mar. 1971, pp. 785806.

11. Wahl, H.W. and Kasiba, R.J., „Design and Construction Aspects of Large Pre-stressed Concrete (PWR) Containment Vessels", ACI Journal, Vol. 66, No. 5, May 1969.

12. Lin, C.S., „Nonlinear Analysis of Reinforced Concrete Slabs and Shells”, Ph. D. thesis, Univ. of California, Berkeley, Calif, 1973.

13. Kamal, M., Tawfik, and El demerdash, „Behavior and Repair of Reinforced Concrete Cylindrical Shell Roofs", AlAzhar University, Cairo, Egypt, 1991.

14. Foraboshi, P., Borri, C., and Chiarugi, A., „Structural Analysis and Rehabilitation of Reinforced Concrete Shells", ACI Journal, Vol. 92, No. 2, March-April 1995.

15. Lackner, R., and Mang, H.A., „Adaptive FE Analysis of RC Shells,” Journal of Engineering Mechanics, Vol. 127, No. 12, December 2002.

16. Bashandy, A.A., „Repair and Strengthening of Reinforced Concrete Shell Structures”, M. Sc. thesis, Menoufiya Univ., Menoufiya, Egypt, 2004.

17. Kamal, M.M., Tayel, M., Meleka, N.N., Bashandy, A.A., „Experimental Evaluation of Repair and Strengthening Techniques of Elliptical Paraboloid Reinforced Concrete Shells," Civil Engineering Research Magazine CERM, Azhar University, Egypt, Vol. 29, No. 2, 2007.

18. Meleka, N.N., „Nonlinear Analysis of Flat Slabs”, Ph. D. thesis, Menoufiya Univ., Egypt, 1995. 